\title{
Novel Catalytic Dielectric Barrier Discharge Reactor for Gas-Phase Abatement of Isopropanol
}

\author{
Ch. Subrahmanyam $\cdot$ A. Renken $\cdot$ L. Kiwi-Minsker
}

Received: 22 March 2006/ Accepted: 5 September 2006/

Published online: 20 December 2006

(C) Springer Science+Business Media, LLC 2006

\begin{abstract}
Catalytic gas-phase abatement of air containing $250 \mathrm{ppm}$ of isopropanol (IPA) was carried out with a novel dielectric barrier discharge (DBD) reactor with the inner catalytic electrode made of sintered metal fibers (SMF). The optimization of the reactor performance was carried out by varying the voltage from 12.5 to $22.5 \mathrm{kV}$ and the frequency in the range $200-275 \mathrm{~Hz}$. The performance was significantly improved by modifying SMF with Mn and Co oxide. Under the experimental conditions used, the $\mathrm{MnO}_{x} / \mathrm{SMF}$ showed a higher activity towards total oxidation of IPA as compared to $\mathrm{CoO}_{x} / \mathrm{SMF}$ and SMF electrodes. The complete destruction of $250 \mathrm{ppm}$ of IPA was attained with a specific input energy of $\sim 235 \mathrm{~J} / \mathrm{L}$ using the $\mathrm{MnO}_{x} / \mathrm{SMF}$ catalytic electrode, whereas, the total oxidation was achieved at $760 \mathrm{~J} / \mathrm{L}$. The better performance of the $\mathrm{MnO}_{x} / \mathrm{SMF}$ compared to other catalytic electrodes suggests the formation of short-lived active species on its surface by the in-situ decomposition of ozone.
\end{abstract}

Keywords Volatile organic compound abatement $\cdot$ Non-thermal plasma Dielectric barrier discharge $\cdot$ Plasma-assisted catalysis $\cdot$ Sintered metal fibers

\section{Introduction}

Isopropanol (IPA) is one of the commonly used solvents in electronic industry for cleaning the printed circuit boards and LCD monitors [1]. The recommend exposure limit for IPA in the work place is $400 \mathrm{ppm}$; higher concentration causes health problems like irritation of eyes, drowsiness, and dizziness. Therefore, a lot of effort has been made in the development of methods for the abatement of this compound [2]. IPA from industrial effluent can be recovered by adsorption into water using wet scrubbers followed by distillation or pervaporation [3]. Thermal

Ch. Subrahmanyam $\cdot$ A. Renken $\cdot$ L. Kiwi-Minsker $(\bowtie)$

Ecole Polytechnique Fédérale de Lausanne (LGRC-EPFL), Lausanne CH-1015, Switzerland e-mail: lioubov.kiwi-minsker@epfl.ch 
oxidation of alcohols needs a high temperature in the range $600-700{ }^{\circ} \mathrm{C}$, whereas, thermocatalytic decomposition takes place in the temperature range $250-400{ }^{\circ} \mathrm{C}$ $[4,5]$. At low concentrations $(<1000 \mathrm{ppm})$ these techniques are not economically feasible since the complete combustion of diluted VOCs is not possible in the autothermal regime and needs continuous heating of big air volumes. In this context, non-thermal plasma (NTP) produced at atmospheric pressure could be a method of choice. In NTP, the electrical energy is primarily utilized for the production of energetic electrons, leaving the background gas nearly at room temperature [6-13]. In addition, NTP produces active species like radicals, excited molecules and ions. When air is used as the carrier gas, ozone is also formed due to the oxygen ionization [6-16].

The NTP technique has been already tested for the destruction of $135 \mathrm{ppm}$ and $400 \mathrm{ppm}$ of IPA with an input energy of 400 and $700 \mathrm{~J} / \mathrm{L}$, respectively $[17,18]$. However, formation of acetone as a stable secondary product was observed. Acetone destruction by NTP was found to be difficult and took place at higher SIE ( 1100 J/L), which is not energetically favorable [17-19]. Hence, the development of an efficient NTP reactor towards total oxidation of IPA at reasonable input energy remains a challenge.

The NTP technique has been used for the destruction of various VOCs with the reported selectivity to $\mathrm{CO}_{2}$ (total oxidation) of $30-50 \%$, whereas, the target value is $100 \%$. Among different alternatives to improve the efficiency of NTP reaction, plasma combined with a heterogeneous catalyst seems to be a suitable choice [10, 14-16]. In practice, the catalyst can be placed either in the discharge zone (in-plasma catalytic reactor) or after the discharge zone (post-plasma catalytic reactor) [14-16, 20-25]. However, both methods have limitations mainly due to the deactivation of the catalyst by carbonaceous deposits on the surface.

Recently, we reported a novel dielectric barrier discharge (DBD) reactor configuration, where a metallic catalyst made of sintered metal fibers (SMF) serves at the same time as the inner electrode [26, 27]. Destruction of toluene as a model VOC was tested and the complete oxidation of toluene was attained using SMF modified by $\mathrm{MnO}_{x}[26,27]$. This study presents the destruction of $250 \mathrm{ppm}$ of IPA by DBD catalytic reactor aiming on the total IPA oxidation at low input energy $(\mathrm{SIE}<800 \mathrm{~J} / \mathrm{L})$. Influence of various parameters, like the catalyst formulation, applied voltage, frequency and the formation of ozone on the performance of plasma reactor is studied.

\section{Experimental}

\subsection{Materials and Method}

Sintered metal fiber (SMF) filters made of stainless steel (Cr 16-18; Ni 10-13; Mo 2-2.5; Fe balance) in the form of a uniform pore panel (thickness $0.29 \mathrm{~mm}$, porosity of $80 \%$ ) were used as the inner electrode. For the deposition of $3 \mathrm{wt} \% \mathrm{MnO}_{x}$ and $\mathrm{CoO}_{x}$, the SMF was first oxidized at $600{ }^{\circ} \mathrm{C}$ for $4 \mathrm{~h}$, followed by impregnation with $\mathrm{Co}$ and $\mathrm{Mn}$ nitrate aqueous solutions. Drying at room temperature and calcination at $773 \mathrm{~K}$ in air for $5 \mathrm{~h}$ forms metal oxide film supported on SMF. Finally, SMF catalytic filters were subjected to an electrical hot-press treatment to shape them into cylinders with an outer diameter of $11.5 \mathrm{~mm}$.

算 Springer 
Details of the novel DBD reactor with catalytic electrode have been reported elsewhere [26]. Briefly, the dielectric discharge was generated in a cylindrical quartz tube with an inner diameter of $18.5 \mathrm{~mm}$. A silver paste painted on the outer surface of the quartz tube acts as the outer electrode, whereas, a stainless steel SMF filter was used as the inner electrode. Typical discharge length was $10 \mathrm{~cm}$ and discharge gap $3.5 \mathrm{~mm}$. The SIE in the range of 160-760 J/L was applied by varying the AC high voltage $(12.5-22.5 \mathrm{kV})$ and frequency $(200-275 \mathrm{~Hz})$. The voltagecharge (V-Q) Lissajous method was used to determine the discharge power (W) in the DBD reactor, whereas, the SIE of the discharge was calculated using the relation

$$
\operatorname{SIE}(\mathrm{J} / \mathrm{L})=\text { Power }(\mathrm{W}) / \text { gas flow rate }(\mathrm{L} / \mathrm{s})
$$

IPA was introduced with a motor-driven syringe pump and was diluted by a stream of air. The air flow rate was fixed at $500 \mathrm{~mL} / \mathrm{min}$ (STP) using a mass flow controller (MFC). The IPA input concentration was varied between 100 and $1000 \mathrm{ppm}$ by adjusting the flow rate. Air containing IPA was fed into the plasma reactor through a Teflon tube. The IPA concentration was measured at the outlet by a gas chromatograph (Shimadzu $14 \mathrm{~B}$ ) equipped with a FID. The formation of $\mathrm{CO}_{2}$ and $\mathrm{CO}$ during IPA destruction was simultaneously measured by an infrared gas analyzer (Siemens Ultramat 21-P), and the ozone formed in the plasma reactor was measured with an UV absorption ozone monitor (API-450 NEMA). As the volume change due to chemical reaction is negligible, the selectivities to $\mathrm{CO}, \mathrm{CO}_{2}$ and $\mathrm{CO}_{x}$ can be expressed as:

$$
\begin{gathered}
S_{\mathrm{CO}}(\%)=\frac{[\mathrm{CO}]}{3 \cdot\left([\mathrm{IPA}]_{0}-[\mathrm{IPA}]\right)} * 100 \\
S_{\mathrm{CO}_{2}}(\%)=\frac{\left[\mathrm{CO}_{2}\right]}{3 \cdot\left([\mathrm{IPA}]_{0}-[\mathrm{IPA}]\right)} * 100 \\
S_{\mathrm{CO}_{x}}(\%)=S_{\mathrm{CO}}(\%)+S_{\mathrm{CO}_{2}}(\%)
\end{gathered}
$$

where $[\mathrm{CO}]$ and $\left[\mathrm{CO}_{2}\right]$ are the outlet concentrations of $\mathrm{CO}$ and $\mathrm{CO}_{2}$, respectively, and [IPA $]_{0}$ and [IPA] - the initial and final isopropanol concentrations. As partially oxidized products were not observed in the present work, $S_{\mathrm{CO}_{x}}$ also represents the mass balance of the gaseous products. In order to confirm the formation of transition metal oxides on SMF surface, the XPS analysis of the modified catalytic SMF filters was carried out using an Axis Ultra ESCA system (Kratos, Manchester) with monochromated $\mathrm{Al}-\mathrm{K}_{\alpha}$ radiation $(1486.6 \mathrm{eV})$ and reported in our earlier publication [26].

\section{Results and Discussion}

\subsection{Discharge Characterization}

Figure 1a represents a typical V-Q Lissajous figure for $22.5 \mathrm{kV}$ and $275 \mathrm{~Hz}$. The area of the Lissajous figure characterizes the energy dissipated during one period of 

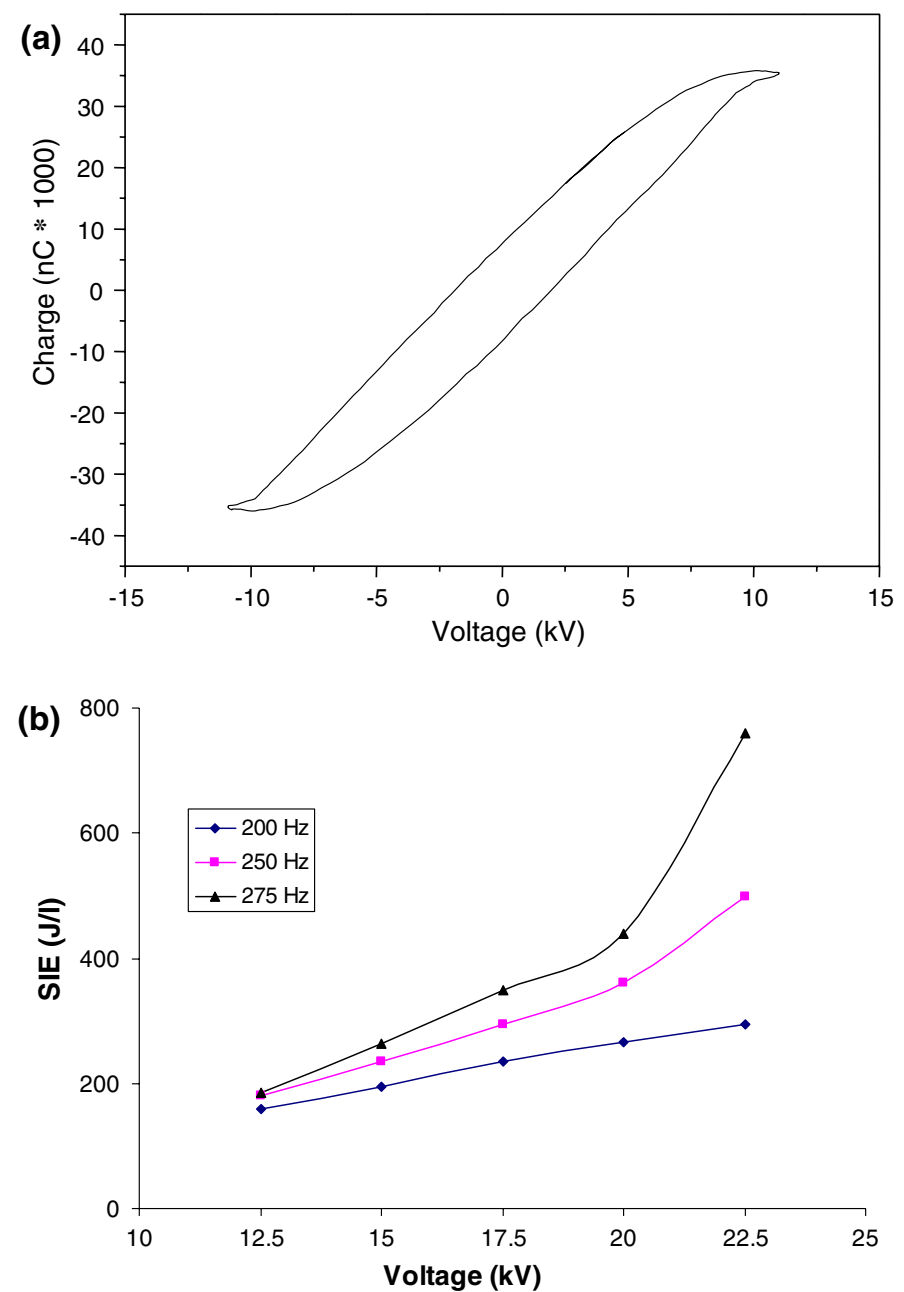

Fig. 1 (a) V-Q Lissajous figure of the DBD reactor for $22.5 \mathrm{kV}$ and $275 \mathrm{~Hz}$ (b) Variation of SIE as a function of applied voltage and frequency

the voltage. Figure $1 \mathrm{~b}$ represents the variation of SIE as a function of the applied voltage in the range $12.5-22.5 \mathrm{kV}$ and frequency $200-275 \mathrm{~Hz}$. As seen from Fig. 1b, increasing the applied voltage at a constant frequency increases the power and thereby, the SIE. For example, at $200 \mathrm{~Hz}$, the SIE increased from $160 \mathrm{~J} / \mathrm{L}(12.5 \mathrm{kV})$ to $295 \mathrm{~J} / \mathrm{L}(22.5 \mathrm{kV})$. When the frequency was increased to $250 \mathrm{~Hz}$, a considerable increase up to $500 \mathrm{~J} / \mathrm{L}$ was observed. With further increasing frequency to $275 \mathrm{~Hz}$, the SIE reaches a maximum value of $760 \mathrm{~J} / \mathrm{L}$ at $22.5 \mathrm{kV}$.

\subsection{Effect of Initial Isopropanol Concentration on the Performance of SMF Catalytic Electrodes at $195 \mathrm{~J} / \mathrm{L}$}

Figure 2a shows the comparative activity of SMF electrodes as a function of IPA initial concentration varied between 100 and $1000 \mathrm{ppm}$. The experiments were 篮 Springer 

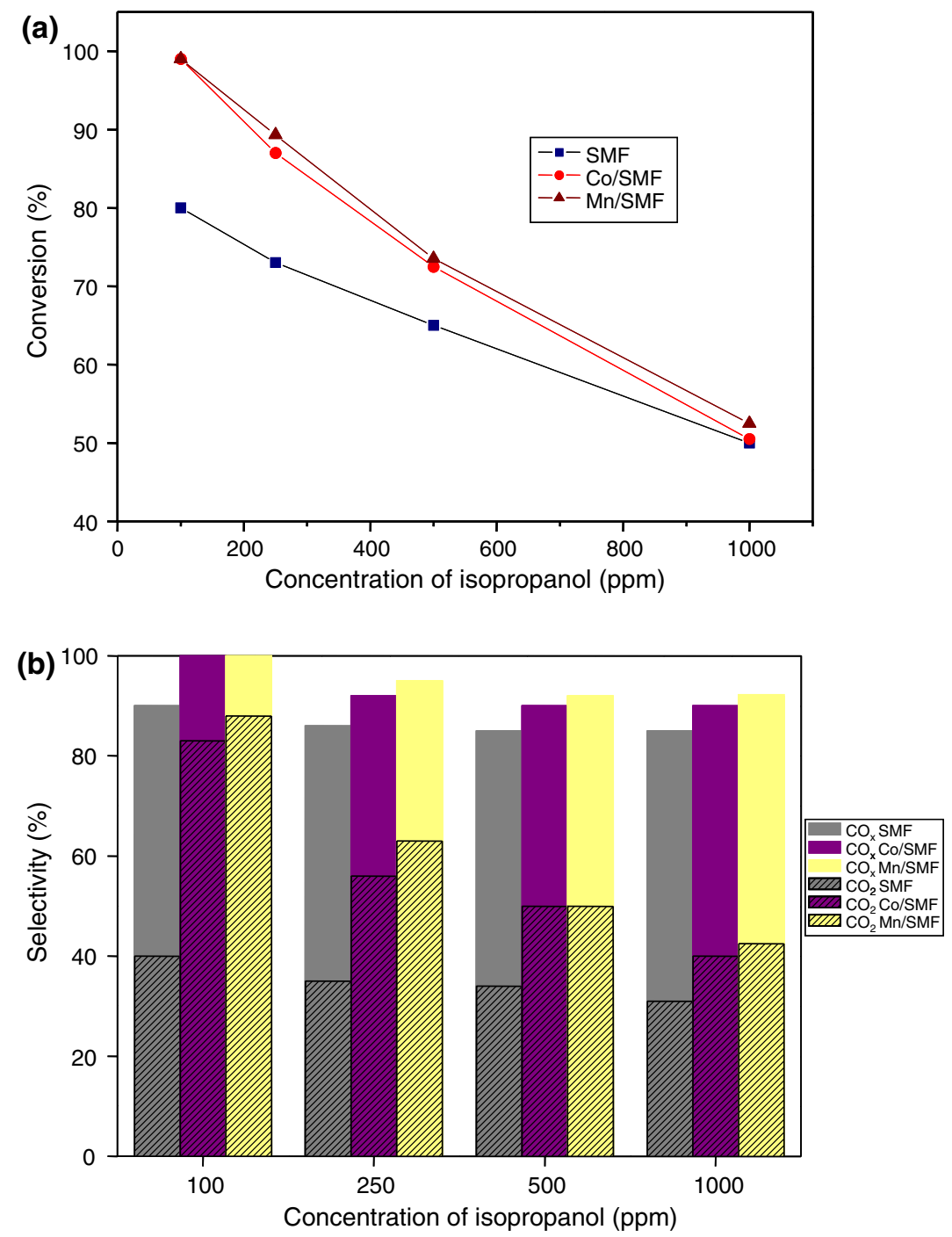

Fig. 2 Influence of initial IPA concentration at SIE of $195 \mathrm{~J} / \mathrm{L}(15 \mathrm{kV}$ and $200 \mathrm{~Hz})$ on (a) conversion (b) selectivity to different products over the SMF electrodes

carried out at a voltage of $15 \mathrm{kV}$ and a frequency of $200 \mathrm{~Hz}$ that corresponds to a SIE of $195 \mathrm{~J} / \mathrm{L}$. As seen from the Fig. 2a, the conversion decreases with increasing isopropanol concentration. For example, during the destruction of $100 \mathrm{ppm}$ of isopropanol, SMF catalytic electrode showed $\sim 80 \%$ conversion, which decreased to $\sim 50 \%$ for $1000 \mathrm{ppm}$. A similar trend was also observed for the DBD reactor with $\mathrm{CoO}_{x}$ and $\mathrm{MnO}_{x}$ electrodes.

Figure $2 \mathrm{~b}$ shows the selectivity to the gaseous products $\left(\mathrm{CO}_{x}, \mathrm{CO}_{2}+\mathrm{CO}\right)$, as a function of IPA concentration (100-1000 ppm) at $195 \mathrm{~J} / \mathrm{L}(15 \mathrm{kV}$ and $200 \mathrm{~Hz})$. Since partially oxidized gaseous products were not observed $\left(\mathrm{CO}_{2}\right.$ and $\mathrm{CO}$ are the only gaseous products formed), the solid deposited on the walls of the reactor completes 
the total carbon balance. Hence, as shown in Fig. 2b, for 100 ppm of IPA, at SIE $195 \mathrm{~J} / \mathrm{L}$, using SMF electrode, nearly $90 \%$ of IPA was oxidized to gaseous products, whereas, for $1000 \mathrm{ppm}$ it was slightly decreased to $80 \%$ and the rest $(-20 \%)$ was in the form of undesired solid deposit. Interesting observation is that at $100 \mathrm{ppm}$, metal oxide modified SMF electrodes showed $\sim 100 \%$ selectivity to $\mathrm{CO}_{x}$. Figure $2 \mathrm{~b}$ also represents the selectivity to $\mathrm{CO}_{2}$, which decreases significantly with increasing IPA concentration: for $100 \mathrm{ppm}$, the SMF electrode showed $\sim 40 \%$ selectivity to $\mathrm{CO}_{2}$ and dropped to $\sim 30 \%$ for $1000 \mathrm{ppm}$. Metal oxides (Mn, Co) supported on SMF showed higher selectivity to $\mathrm{CO}_{2}$ especially for IPA concentration $<500 \mathrm{ppm}$. For example, during the destruction of $250 \mathrm{ppm}$ of IPA, the $\mathrm{MnO}_{x} / \mathrm{SMF}$ electrode showed $\sim 60 \%$ selectivity to $\mathrm{CO}_{2}$ against only $\sim 30 \%$ with the SMF electrode. As explained earlier, the NTP technique would be beneficial for the abatement of diluted VOCs. Further studies were carried out at $250 \mathrm{ppm}$ of IPA to optimize the performance of the SMF catalytic electrode to reach total oxidation of IPA to $\mathrm{CO}_{2}$.

\subsection{Influence of Applied Voltage on the Destruction of $250 \mathrm{ppm}$ of Isopropanol over Catalytic SMF Electrodes}

Conversion of $250 \mathrm{ppm}$ of IPA was studied as a function of applied voltage varied in the range of $12.5-22.5 \mathrm{kV}$ at a fixed frequency of $200 \mathrm{~Hz}$ over catalytic SMF electrodes and results were presented in Fig. 3a. These conditions correspond to the SIE of 160 and $295 \mathrm{~J} / \mathrm{L}$, respectively. As seen from Fig. 3a, the IPA conversion increases with the increasing applied voltage. However, at a particular SIE, metal oxide supported SMF electrodes showed higher conversion compared to SMF unmodified electrode. With the SMF electrode the IPA conversion reaches $100 \%$ only at $22.5 \mathrm{kV}(295 \mathrm{~J} / \mathrm{L})$, whereas, with Co and Mn oxides supported on SMF, it was achieved at $265 \mathrm{~J} / \mathrm{L}$ and $235 \mathrm{~J} / \mathrm{L}$, respectively. A similar observation was made earlier during the destruction of toluene, where $\mathrm{MnO}_{x} / \mathrm{SMF}$ electrode showed better performance compared to $\mathrm{CoO}_{x} / \mathrm{SMF}$ and SMF electrodes [26]. This better performance of $\mathrm{MnO}_{x} / \mathrm{SMF}$ might be due to the formation of active oxygen species on metal oxide surface due to in-situ decomposition of ozone [6, 27].

Figure $3 \mathrm{~b}$ represents the selectivity towards $\mathrm{CO}_{x}$ and $\mathrm{CO}_{2}$ formed in the above experiments. As seen, during the destruction of $250 \mathrm{ppm}$ of IPA, metal oxide supported SMF electrodes showed $\sim 100 \% \mathrm{CO}_{x}$ selectivity (no carbon deposit) at $17.5 \mathrm{kV}$ that corresponds to a SIE $235 \mathrm{~J} / \mathrm{L}$, whereas, with the non modified SMF this was achieved only at $295 \mathrm{~J} / \mathrm{L}(22.5 \mathrm{kV})$. Figure $3 \mathrm{~b}$ also represents the selectivity to $\mathrm{CO}_{2}$, which also followed the same trend as conversion and $\mathrm{CO}_{x}$ selectivity. At any voltage, $\mathrm{MnO}_{x} / \mathrm{SMF}$ electrode showed higher $\mathrm{CO}_{2}$ selectivity compared to $\mathrm{CoO}_{x} /$ SMF and SMF. During the present study, at $22.5 \mathrm{kV}(295 \mathrm{~J} / \mathrm{L}), \sim 75 \% \mathrm{CO}_{2}$ selectivity was achieved on $\mathrm{MnO}_{x} / \mathrm{SMF}$. A total conversion of $250 \mathrm{ppm}$ of IPA with no carbon deposit was observed in this case (Fig. 3a, b).

\subsection{Influence of Applied Voltage and Frequency on the Performance of $\mathrm{MnO}_{x} / \mathrm{SMF}$ Catalytic Electrode during the Destruction of $250 \mathrm{ppm}$ of Isopropanol}

In the previous study, $\mathrm{MnO}_{x}$ catalytic electrode showed a better performance over other catalytic electrodes during the destruction of $250 \mathrm{ppm}$ of IPA in the SIE range 160-295 J/L at a fixed frequency of $200 \mathrm{~Hz}$. Further studies were aimed at achieving 


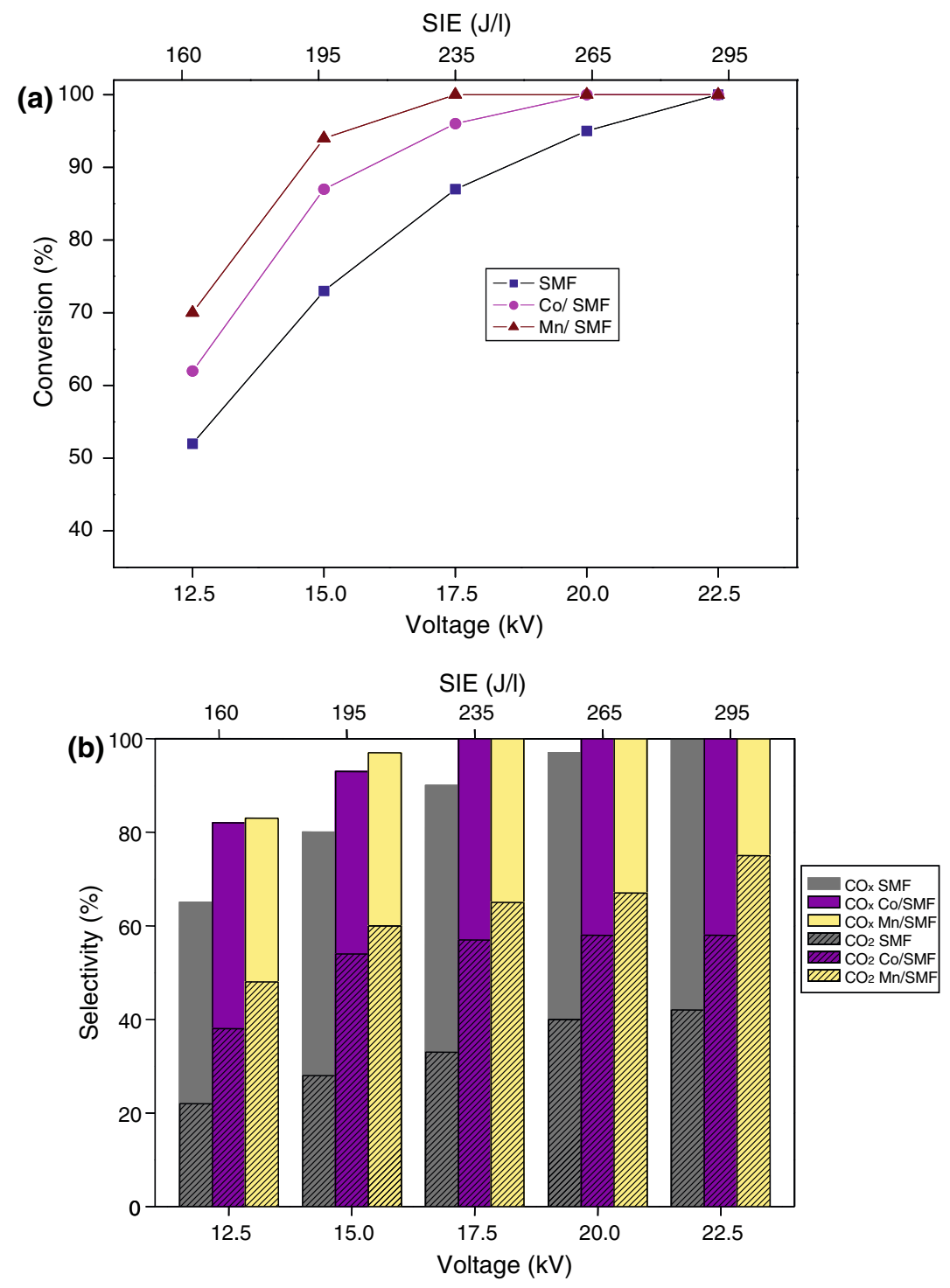

Fig. 3 Influence of voltage on (a) conversion (b) selectivity to the gas products (250 ppm of IPA, $12.5-22.5 \mathrm{kV}, 200 \mathrm{~Hz}$ )

the total oxidation of $250 \mathrm{ppm}$ of IPA over $\mathrm{MnO}_{x}$ catalytic electrode. Figure 4a represents relation between the SIE at different applied voltage and frequency and the efficiency of DBD reactor with $\mathrm{MnO}_{x}$ catalytic electrode. The SIE has been varied in the range $160-760 \mathrm{~J} / \mathrm{L}$ by changing the applied voltage between 12.5 and $22.5 \mathrm{kV}$ and frequency in the range $200-275 \mathrm{~Hz}$. As seen from Fig. 4a, at $200 \mathrm{~Hz}$, $\sim 100 \%$ conversion was achieved at a SIE $>235 \mathrm{~J} / \mathrm{L}(17.5 \mathrm{kV})$. However, with increasing frequency to $250 \mathrm{~Hz}$ and $275 \mathrm{~Hz}$, slightly higher SIE was required to attain $\sim 100 \%$ conversion. We assign this observation to the fact that at low voltage 

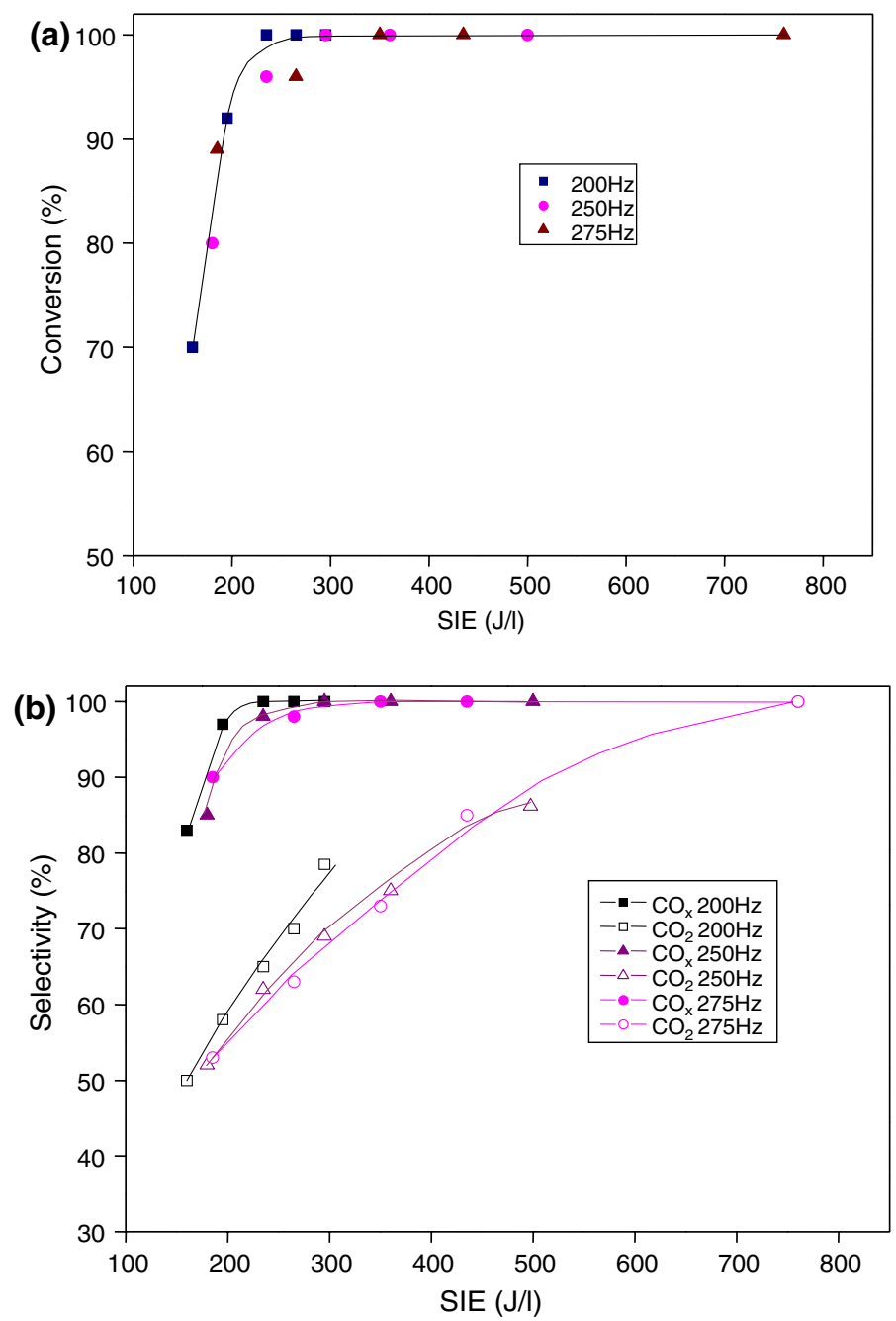

Fig. 4 Influence of $\mathrm{SIE}$ with the $\mathrm{MnO}_{x} / \mathrm{SMF}$ catalytic electrode on (a) conversion of IPA (b) selectivity to the gaseous products (250 ppm of IPA, voltage $12.5-22.5 \mathrm{kV}$ )

and high frequency, the conditions may be close to the ignition threshold and hence, the discharge was not uniform throughout the discharge volume. A similar observation was earlier made during the destruction of toluene in the DBD reactor [27].

Figure $4 \mathrm{~b}$ represents the selectivity profile of the gaseous products during the destruction of IPA as a function of SIE. The selectivity of solid deposits can be estimated as (100- $\left.S_{\mathrm{CO}_{x}}\right) \%$. As seen from Fig. $4 \mathrm{~b}$, increasing both voltage and frequency lead to a higher selectivity to $\mathrm{CO}_{x}$, but also increases SIE. At any frequency, nearly $100 \%$ selectivity to $\mathrm{CO}_{x}$ (with out solid deposit) was achieved at voltage higher $17.5 \mathrm{kV}$. Figure $4 \mathrm{~b}$ also represents the selectivity to $\mathrm{CO}_{2}$, which also increases with increasing SIE. When SIE was varied in the range 160-295 J/L, a maximum of $75 \%$ selectivity to $\mathrm{CO}_{2}$ was achieved at $295 \mathrm{~J} / \mathrm{L}(200 \mathrm{~Hz}, 22.5 \mathrm{kV})$ with $\sim 25 \%$ selectivity to CO. Further increase of SIE to $500 \mathrm{~J} / \mathrm{L}(22.5 \mathrm{kV}$ and $250 \mathrm{~Hz})$, 
Fig. 5 Formation of ozone with the SMF catalytic electrodes (250 ppm IPA in air, $15 \mathrm{kV}$ )

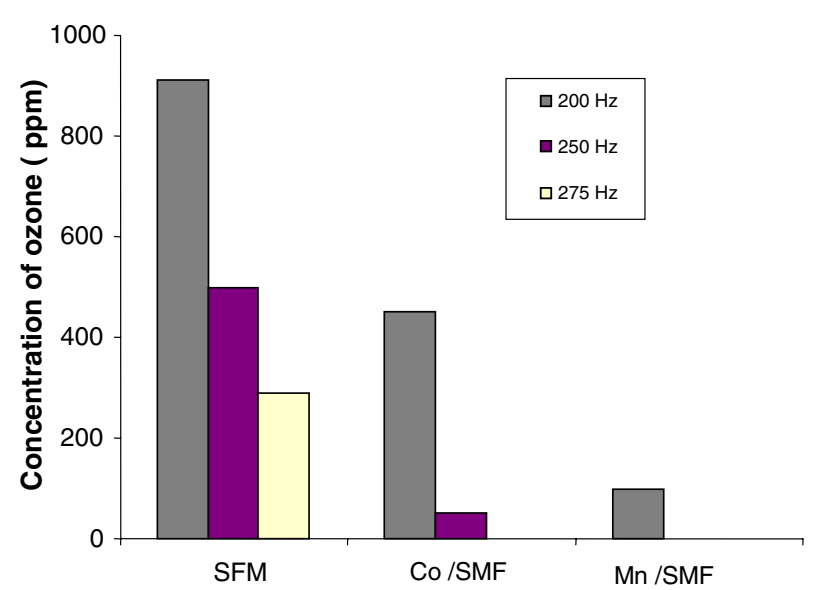

the $\mathrm{CO}_{2}$ selectivity was observed to reach $\sim 85 \%$. Close to $100 \% \mathrm{CO}_{2}$ selectivity (no $\mathrm{CO}$ and carbon deposit) was achieved at $760 \mathrm{~J} / \mathrm{L}(22.5 \mathrm{kV}$ and $275 \mathrm{~Hz})$. Hence, with the novel DBD reactor presented herein, it is possible to oxidize completely $250 \mathrm{ppm}$ of IPA at a threshold SIE value of $760 \mathrm{~J} / \mathrm{L}$.

\subsection{Ozone Formation in the DBD Reactor}

It is known that NTP produces ozone from air by the ionization of oxygen molecules. There is no direct correlation between the amount of ozone formed in the NTP reactor to its efficiency, nevertheless, the oxidation of various hydrocarbons in catalytic plasma reactor might be due to the decomposition of ozone on the catalyst surface leading to the formation of strong oxidizing species, mainly atomic oxygen $[6,9,16,22,23,26,27]$. During the present study, $\mathrm{MnO}_{x} / \mathrm{SMF}$ catalytic electrode showed better performance during the destruction of IPA compared to $\mathrm{CoO}_{x} / \mathrm{SMF}$ and SMF. This observation can be explained based on the ozone decomposition efficiency as presented in Fig. 5, which shows the influence of the catalytic electrodes on in-situ ozone decomposition at $15 \mathrm{kV}$. With increasing frequency, the ozone concentration decreases, and the $\mathrm{MnO}_{x} / \mathrm{SMF}$ is seen to be the most active electrode in ozone decomposition. This suggests the formation of reactive oxygen species using the $\mathrm{MnO}_{x} / \mathrm{SMF}$ catalytic electrode at low energy consumption being responsible for the higher performance observed [6, 28, 29].

\section{Conclusions}

Catalytic abatement of a diluted (250 ppm) isopropanol (IPA) in air was carried out in a novel DBD reactor with a catalytic SMF electrode. The complete destruction of 250 ppm of IPA to $\mathrm{CO}_{x}$ and $\mathrm{H}_{2} \mathrm{O}$ was achieved with a specific input energy (SIE) as low as $\sim 235 \mathrm{~J} / \mathrm{L}(17.5 \mathrm{kV}$ and $200 \mathrm{~Hz})$. Surface modification of SMF electrode with oxides of $\mathrm{Co}$ and $\mathrm{Mn}$ allowed attaining the total IPA oxidation forming only $\mathrm{CO}_{2}$ and $\mathrm{H}_{2} \mathrm{O}$. Among the catalyst studied, $3 \mathrm{wt} \% \mathrm{MnO}_{x} / \mathrm{SMF}$ showed the best performance, where a complete oxidation of IPA was achieved at SIE $\sim 750 \mathrm{~J} / \mathrm{L}$. It has been 
proposed that in-situ decomposition of ozone on $\mathrm{MnO}_{x} / \mathrm{SMF}$ leads to the formation of reactive oxygen species, which are responsible for the observed higher activity of the $\mathrm{MnO}_{x} / \mathrm{SMF}$ catalytic electrode.

Acknowledgments The authors acknowledge the Swiss National Science Foundation ("SCOPES" program) and the Swiss Commission of Technology and Innovation (CTI, Bern) for the financial support.

\section{References}

1. http://www.cdc.gov/niosh/npg/npgd0359.html NIOSH Pocket guide to chemical Hazards, 151 2005

2. Pollution prevention and abatement handbook, World Bank Group (1998) 302

3. AWMA (1992) Air and waste management association, Air pollution engineering manual, Van Nostrand Reinhold. New York

4. Gallardo-Amores JM, Armaroli T, Ramis G, Finocchio E, Busca G (1999) Appl Catal B Environ 22:249

5. John Zink Company (1991) Innovations of catalytic combustion. International symposium on environmental control of combustion processes. Honolulu

6. Futamura S, Einaga H, Kabashima H, Hwan LY (2004) Catal Today 89:89

7. Roland U, Holzer F, Kopinke FD (2002) Catal Today 73:315

8. Futamura S, Zhang A, Prieto G, Yamamoto T (1998) IEEE Trans Ind Appl 34:967

9. Kim HH, Oh SM, Ogata A, Futamura S (2005) Appl Catal B: Environ 56:213

10. Ayrault C, Barrault J, Blin-Simiand N, Jorand F, Pasquiers S, Rousseau A, Tatibouet JM (2004) Catal Today 89:75

11. Eliasson B, Kogelschatz U (1991) IEEE Trans Ind Appl 19:1063

12. Yhang K, Eliasson B, Kogelschatz U (2002) Ind Eng Chem Res 41:1462

13. Kogelschatz U (2003) Plasma Chem Plasma Proc 23:1

14. Holzer F, Roland U, Kopinke FD (2002) Appl Catal B: Evniron 38:163

15. Roland U, Holzer F, Kopinke F.D (2005) Appl Catal B: Environ 58:217

16. Roland U, Holzer F, Kopinke FD (2005) Appl Catal B: Environ 58:227

17. Coogan JJ, Technologie Transfer \# 97023244A-ENG, LANL, Feb. 1997

18. Falkenstein Z (1997) J Adv Oxid Technol 2:223

19. Oda T, Yamashita R, Takahashi T, Masuda S (1996) IEEE Trans Ind Appl 32:118

20. Tevault DE (1987) Plasma Chem Plasma Process 7:231

21. Penetratnte B, Hsiao MC, Bardsley JN, Merrit BT, Vogtlin GE, Kuthi A, Burkhart CP, Bayless JR (1997) Plasma Sources Sci Technol 6:251

22. Yamamoto T, Mizuno IK, Tamori I, Ogata A, Nifuku M, Michalska M, Prieto G (1996) IEEE Trasn Ind Appl 32:100

23. Futamura S, Zhang A, Yamamoto T (1997) J Electrostat 42:51

24. Demidiouk V, Moon SI, Chae JO (2003) Catal Commun 4:51

25. Ogata A, Mizuno K, Kushiyama S, Yamamoto T (1999) Plasma Chem Plasma Process 19:383

26. Subrahmanyam Ch, Magureanu M, Kiwi-Minsker L, Renken A (2006) Appl Catal B: Environ 65:150

27. Subrahmanyam Ch, Kiwi-Minsker L, Renken A (2006) Appl Catal B: Environ 65:157

28. Dhandapani B, Oyama ST (1997) Appl Catal B: Environ 11:129

29. Li W, Gibbs GV, Oyama ST (1998) J Am Chem Soc 120:9041 